\title{
APLIKASI SISTEM ADMINISTRASI KEUANGAN SEKOLAH PADA MADRASAH IBHTIDAIYAH UNGGULAN AR-RIDHO TAJURHALANG
}

\author{
Wahyu Waluyo \\ Program Studi Informatika, Fakultas Teknik dan Ilmu Komputer, Universitas Indraprasta PGRI \\ Jalan Raya Tengah No 80, Kelurahan Gedong, Pasar Rebo, Jakarta Timur \\ tuanwahyu71@gmail.com
}

\begin{abstract}
Abstrak
Pengolahan data administrasi keuangan Madrasah Unggulan Ar-ridho masih menggunakan cara manual sehingga dalam pelaksanaannya kurang optimal. Beberapa kendala yang timbul sebagai akibat dalam pengolahan data secara manual tersebut adalah pembuatan atau penyajian dan tidak dapat dilakukan dengan cepat, kemungkinan kesalahan proses pengolahan data dapat terjadi. sehingga mengakibatkan tidak terkontrolnya data pembayaran spp, ujian, dan pembayaran daftar ulang. Metode penelitian yang digunakan adalah Metode grounded research yaitu melakukan penelitian berdasarkan fakta dan menggunakan analisis perbandingan dengan tujuan mengadakan menetapkan konsep, membuktikan teori, mengembangkan teori, pengumpulan dan analisis data dalam waktu bersamaan. Hasil dari penelitian ini adalah berupa Aplikasi Administrasi Keuangan Sekolah Madrasah Ibhtidaiyah Unggulan Ar-ridho Tajurhalang yang meliputi proses pendataan siswa, spp, ujian dan daftar ulang. Aplikasi Administrasi Keuangann Sekolah ini menyediakan beberapa fasilitas yang dapat digunakan oleh pengguna yaitu meliputi input data dan laporan data yang diharapkan dapat mempermudah dan mempercepat proses pengolahan data administrasi keuangan serta pembuatan laporan yang lebih akurat, cepat dan tepat waktu Yang bertujuan untuk menganalisis proses administasi keuangan sekolah yang terdapat pada Madrasah Unggulan Ar-ridho Tajurhalang yang masih menggunakan cara manual dalam pencatatannya untuk diperbaharui menjadi sistem terkomputerasi sehingga memudahkan tata usaha dalam pengerjaannya.
\end{abstract}

Kata Kunci: Aplikasi, Sistem, Administrasi, Keuangan

\begin{abstract}
The processing of financial administration data of Madrasah Ar-ridho still uses manual means so that in its implementation is not optimal. Some of the constraints that arise as a result of manual data processing are the creation or presentation and not be done quickly, the possibility of data processing process errors may occur. resulting in uncontrolled spp payment data, exams, and re-listing payments. The research method used is the grounded research method which is to conduct fact-based research and use comparison analysis with the aim of establishing concepts, proving theories, developing theory, collecting and analyzing data at the same time. The results of this study are in the form of The Financial Administration Application of Madrasah Ibhtidaiyah School Ar-ridho Tajurhalang which includes the process of logging students, spp, exams and re-listing. The Application of Financial Administration of the School provides several facilities that can be used by users, including data input and data reports that are expected to facilitate and speed up the process of processing financial administration data as well as the creation of more accurate, fast and timely reports that aim to analyze the school financial administrative process found in Madrasah Ar-ridho Tajurhalang which still uses manual methods in its recording to be updated into a computerized system so as to facilitate the administration of business in its work.
\end{abstract}

Keyword: Application, System, Administration, Finance

\section{PENDAHULUAN}

Berbagai macam aktivitas manusia sudah banyak yang bersentuhan langsung dengan komputer, terutama kegiatan untuk mengumpulkan data dan pengolahan data serta keinginan untuk mendapatkan data atau informasi agar menjadi lebih mudah dan cepat dilakukan. Hal ini memiliki kaitan erat dengan teknologi komputer untuk mempermudah dalam pembuatan data atau penyimpanan data yang telah maju dan berkembang maka komputer pada saat ini telah dijadikan acuan sebagai alat bantu untuk mempermudah dalam dunia pendidikan misalnya seperti Madrasah Unggulan AR-RIDHO Tajurhalang yang masih menggunakan penyimpanan data sistem 
administrasi keuangan masih manual hingga sangat rentan kehilangan data. Menurut (Mulyadi, 2016) sistem adalah suatu jaringan prosedur yang dibuat menurut pola yang terpadu untuk melaksanakan kegiatan pokok perusahaan. Untuk memenuhi kebutuhan tersebut, maka sudah seharusnya administrasi keuangan mulai menggunakan pemanfaatan teknologi informasi seperti komputer beserta program aplikasi lainnya. Menurut (Ibrahim, 2013) Aplikasi dapat diartikan sebagai suatu program berbentuk perangkat lunak yang berjalan pada suatu sistem tertentu yang berguna untuk membantu berbagai kegiatan yang dilakukan oleh manusia.

Tujuan dari penelitian ini adalah menghasilkan sistem pengolahan data administrasi keuangan yang dapat menginput, menyimpan, menghapus, mengedit dan mencetak data untuk dijadikan laporan administrasi keuangan lebih akurat, cepat dan tepat waktu. Selain itu tujuan penelitian ini adalah Membangun aplikasi sistem administrasi keuangan sekolah menggunakan bahasa pemrograman Java dan database MySQL. Menurut (Heru, 2019) Java adalah bahasa pemrograman yang dapat dijalankan di berbagai komputer termasuk telepon genggam. Bahasa ini awalnya dibuat oleh James Gosling saat masih bergabung di Sun Microsystems saat ini merupakan bagian dari Oracle dan dirilis tahun 1995. Menurut (Arif, 2019) MySQL adalah sebuah software atau perangkat lunak system manajemen berbasis data SQL atau juga multi user dan DBMD Multithread. Pada dasarnya, MySQL ini sebenarnya adalah turunan yang berasal dari salah satu konsep utama dalam database yang memang telah ada sebelumnya yaitu SQL atau Structured Query Language.

Manfaat dari penelitian ini adalah aplikasi yang dibuat dapat dapat membantu kinerja petuhas dan sekolah secara efektif juga efisien, memberi kemudahan pengolahan data administrasi keuangan sekolah dalam penyimpanannya secara cepat dan akurat, dapat mengoptimalkan kinerja para petugas, dan sekolah dalam menangani berkas-berkas administratif data pengolahan data keuangan sekolah. Dengan penelitian ini peneliti memberikan suatu perbedaan yang baru agar lebih inovatif juga efisien dari penelitian sebelumnya yang di dapat, pada aplikasi sistem administrasi keuangan di sekolah dalam penelitian ini memberikan fitur pencarian data yang lebih lengkap untuk memudahkan petugas, sehingga data yang didapat juga lebih akurat. Pemrosesan data yang diberikan terintegrasi dengan database menggunakan MySQL sehingga data yang diolah juga dikontrol dengan baik.

\section{PENELITIAN RELEVAN}

Penelitian yang dilakukan oleh (Wulansari et al., 2013) dengan judul Sistem Informasi Pengelolaan Keuangan pada SMK PGRI 1 Pacitan. Hasil dari penelitian ini sebuah sistem administrasi keuangan sekolah yang digunakan untuk membantu dan mempermudah pengguna dalam melakukan proses pengolahan keuangan sekolah dapat diolah secara efektif, efisien dan akurat.

Penelitian yang dilakukan oleh (Susanti, 2017) dengan judul Sistem Informasi Administrasi Keuangan pada SMK YP17 selorejo. Hasil dari penelitian ini menghasilkan sebuah sistem yang dapat mempermudah dan mempecepat kinerja pengguna sistem untuk mengolah data dengan menginput, menyimpan dan mencetak data sesuai kebutuhan untuk dijadikan laporan dan menyajikan informasi pada siswa.

\section{METODE PENELITIAN}

Metode penelitian yang digunakan adalah Metode grounded research yaitu melakukan penelitian bedasarkan fakta dan menggunakan analisis perbandingan dengan tujuan mengadakan menetapkan konsep, membuktikan teori, mengembangkan teori, pengumpulan dan analisis data dalam waktu bersamaan.

Berikut adalah tahap-tahap penelitian yang peneliti lakukan: 


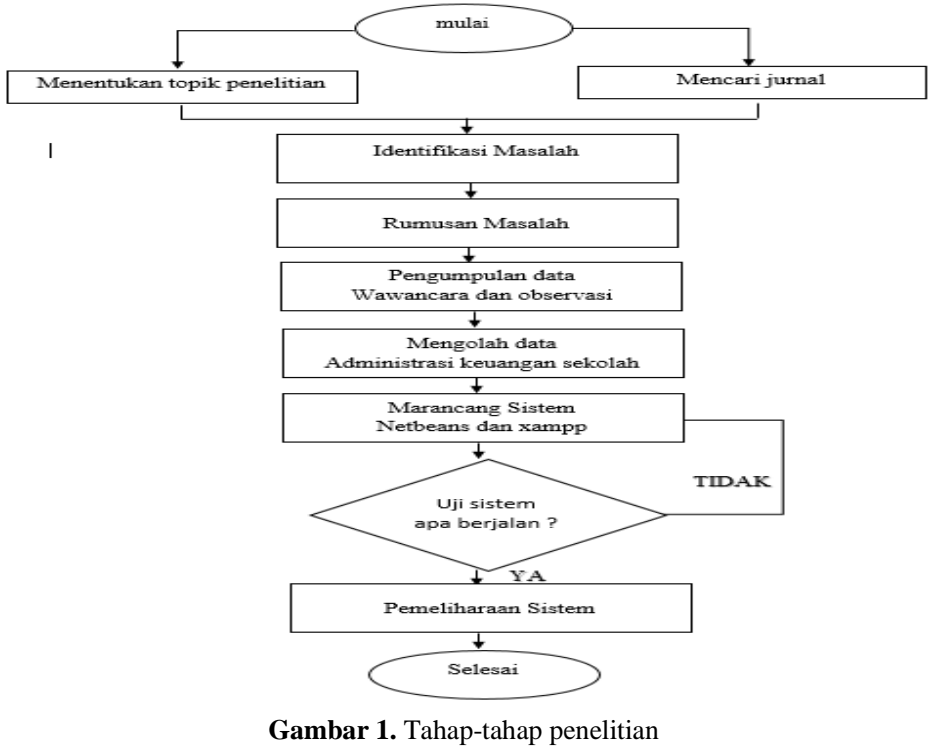

1. Analisis kebutuhan

Pada proses ini peneliti mulai melakukan analisis kebutuhan peangkat lunak apa saja yang dibutuhkan untuk menjalankan aplikasi yang akan peneliti buat. Peneliti mecatatat dan merefernsikan segala kebutuhan perangkat lunak yang akan digunakan sehingga memudahkan dalam pembuatan aplikasi

2. Desain sistem

Peneliti menganalisa kebutuhan sistem yang dilakukan dengan pengumpulan data dengan berfokus pada aplikasi, meliputi informasi, fungsi masing-masing pada bagian sistem, cara kerja, antar muka (User Interface), lalu menyediakan perangkat dan teknik yang dapat membantu peneliti untuk menentukan kebutuhan aplikasi administrasi keuangan sekolah berbasis java dalam melakukan pengolahan data.

3. Implementasi atau pengkodean

peneliti melakukan pembuatan program dengan menggunakan bahasa pemrograman java yang terhubung dengan database MySQL. Dari proses ini, peneliti membuat program dari hasil proses analisa dan pembuatan desain aplikasi yang telah dibuat sebelumnya.

\section{HASIL DAN PEMBAHASAN}

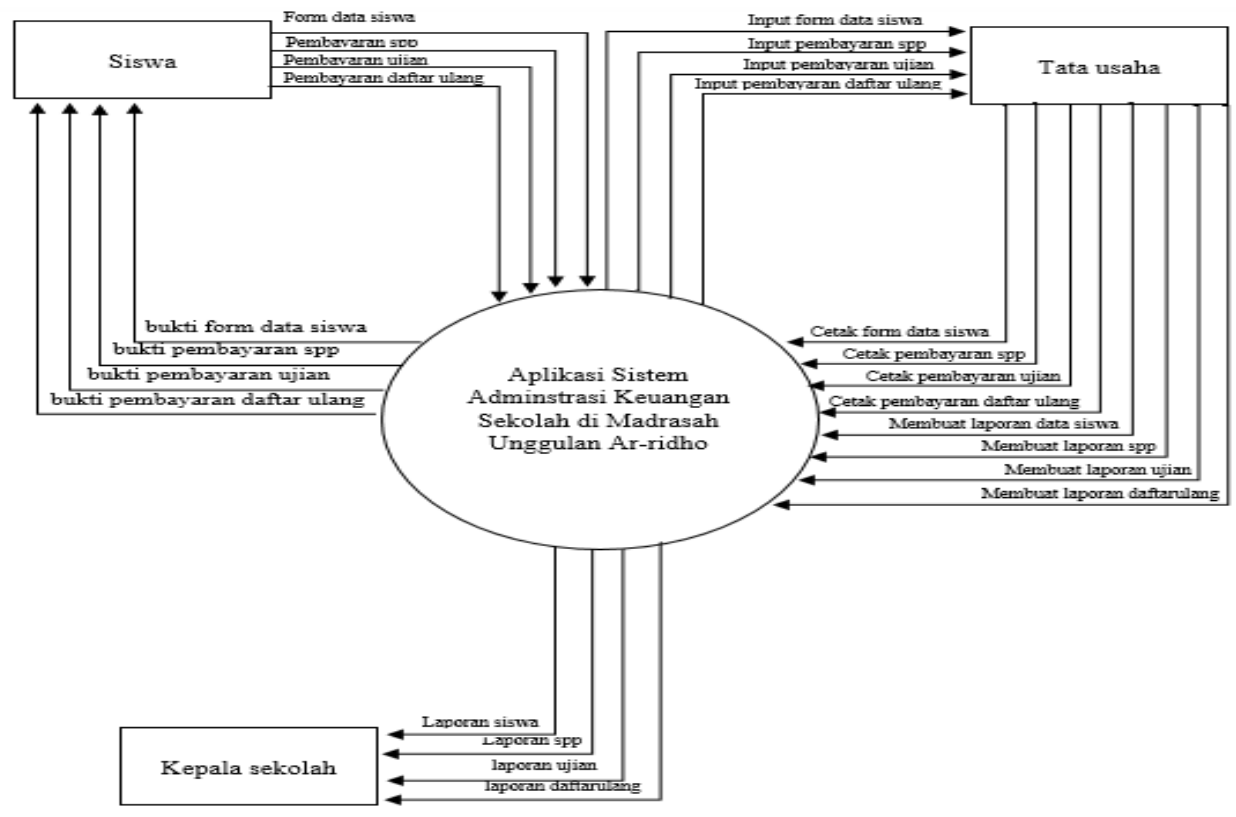

Gambar 2. Diagram Konteks Sistem yang Diusulkan 
Diagram konteks yang mencakup masukan-masukan dasar, sistem umum dan keluaran, diagram ini merupakan tingkatan tertinggi dalam diagram aliran data dan hanya memuat satu proses, menunjukan sistem secara keseluruhan.

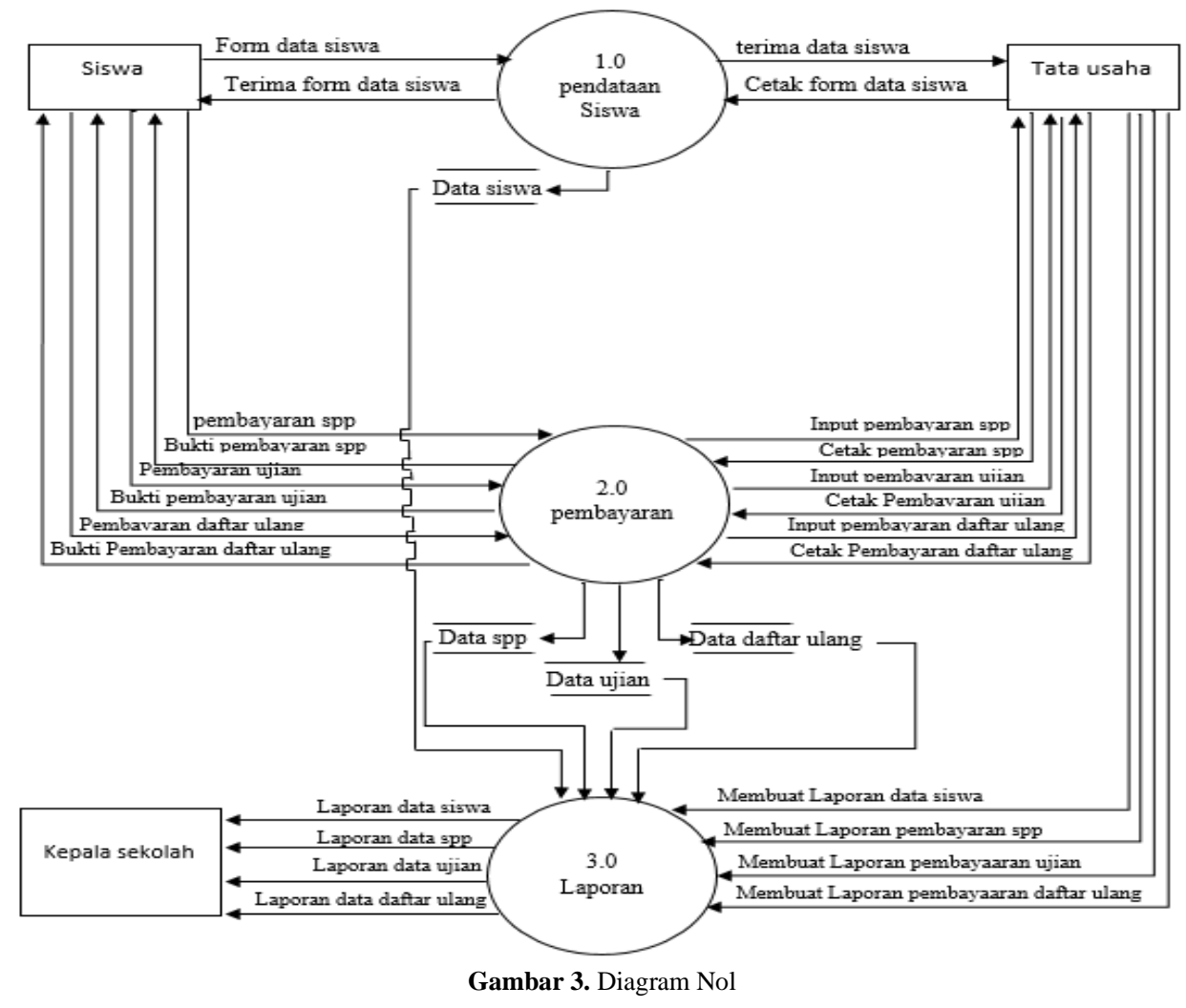

Diagram yang menggambarkan proses dari dataflow diagram. Diagram nol memberikan pandangan secara menyeluruh mengenai sistem yang ditangani, menunjukan tentang fungsi-fungsi utama atau proses yang ada, aliran data, dan eksternal entity.

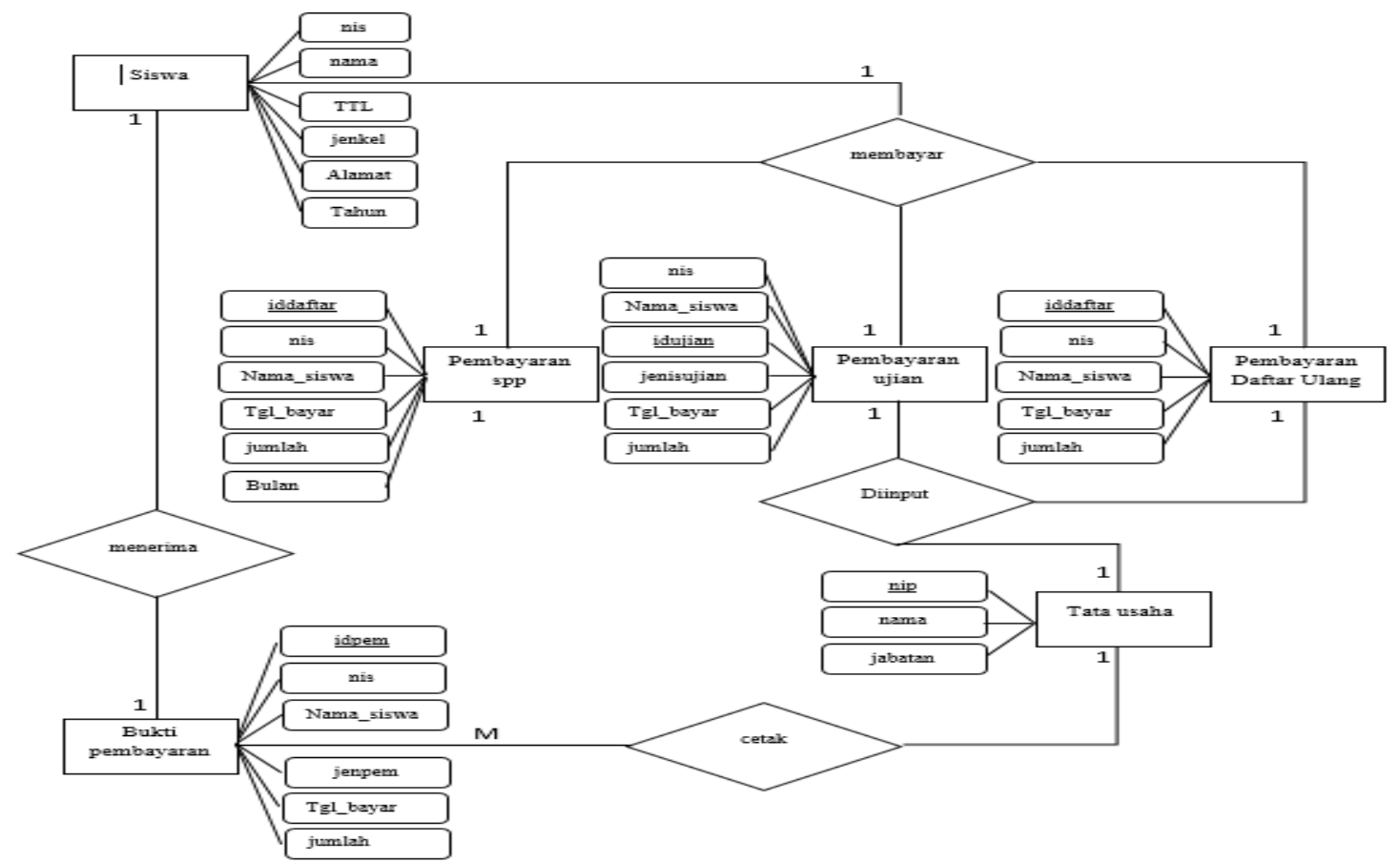

Gambar 4. Entity Relationship Diagram 
ERD menggambarkan hubungan antara satu entitas yang memiliki sejumlah atribut dengan entitas yang lain dalam suatu sistem yang terintegrasi. ERD ini juga akan membantu pada saat melakukan analisis dan perancangan database, karena model data ini akan menunjukkan bermacam-macam data yang dibutuhkan dan hubungan antar data.

\section{Tampilan Layar}

Berikut Berikut tahap implementasi dan pengujian pada software program yang telah di buat dengan bahasa pemrogram Java.

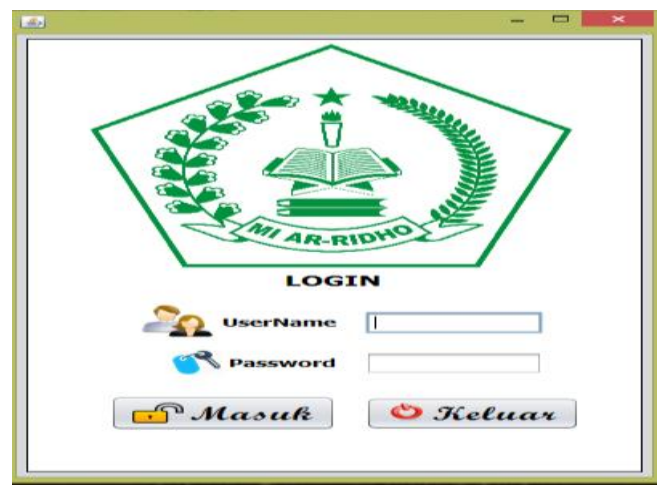

Gambar 5. Login

Menu login merupakan tampilan depan dalam program ini dimana setiap petugas tata usaha harus memasukan username dan password untuk mengakses program administrasi keuangan ini, jika username dan password salah maka petugas tata usaha tidak dapat menggunakan program.

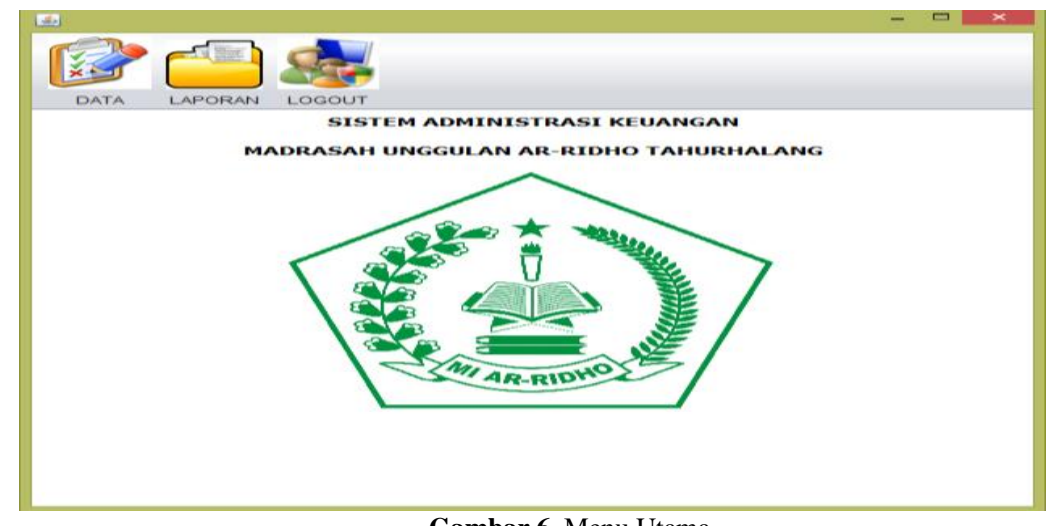

Gambar 6. Menu Utama

Setelah sistem berhasil login maka akan timbul form menu utama yang berisi menu-menu program seperti pengimputan dan melihat data siswa ,data spp ,data ujian, data daftar ulang.

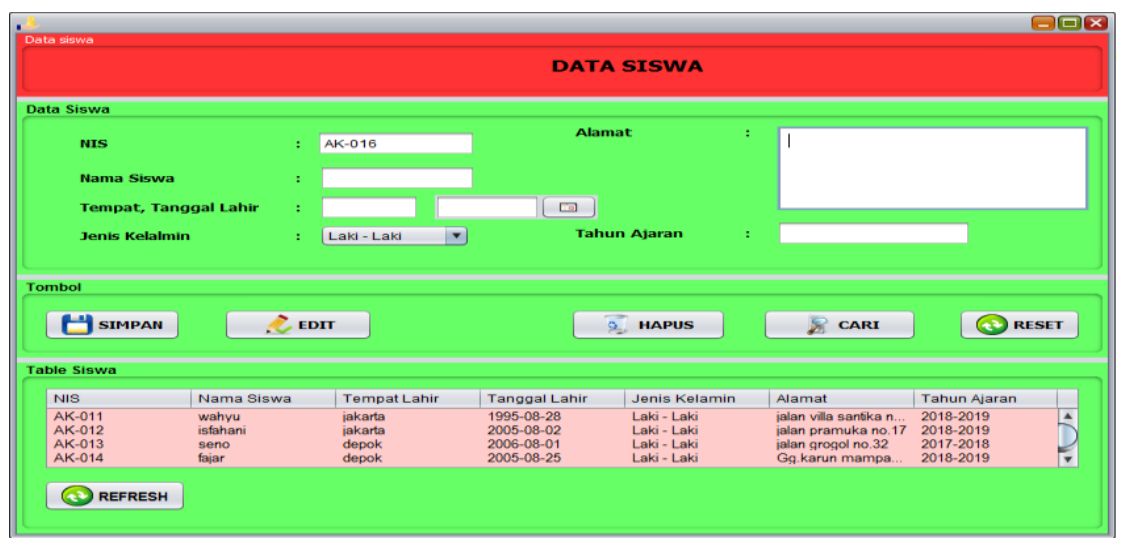

Gambar 7. Menu Data Siswa 
Menu input data siswa merupakan form tampilan yang digunakan untuk memasukan data siswa, selain menyimpan data siswa, user juga dapat mengubah, mencari dan menghapus data siswa.

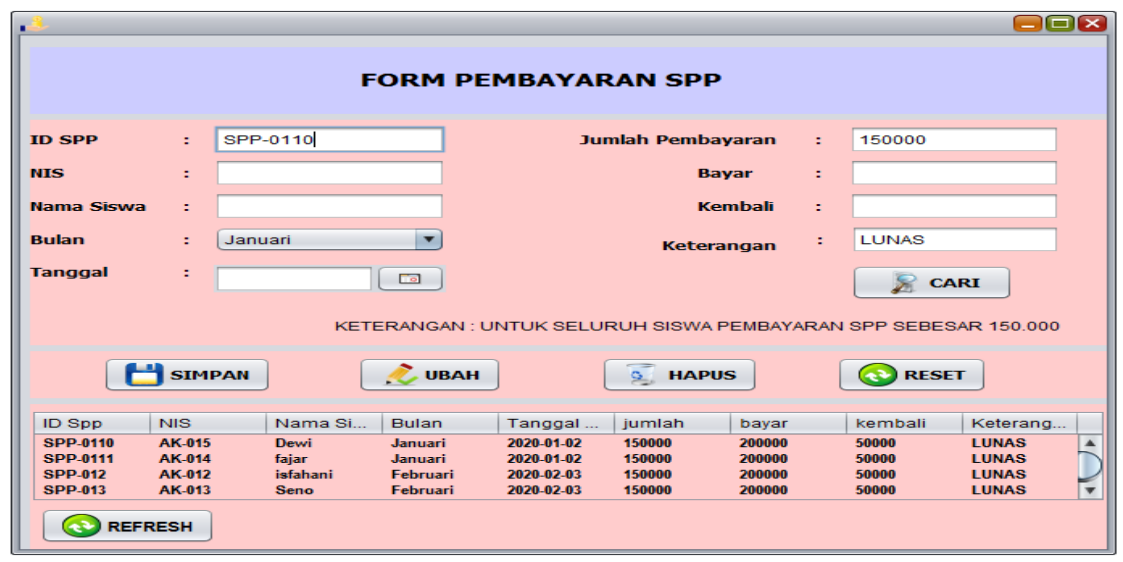

Gambar 8. Menu Data SPP

Menu input form data pembayaran spp merupakan form tampilan yang digunakan untuk memasukan data pembayaran spp, selain menyimpan data spp, user juga dapat mengubah, mencari dan menghapus data siswa. Input form data pembayaran spp nantinya digunakan sebagai sebagai bukti pembayaran spp.

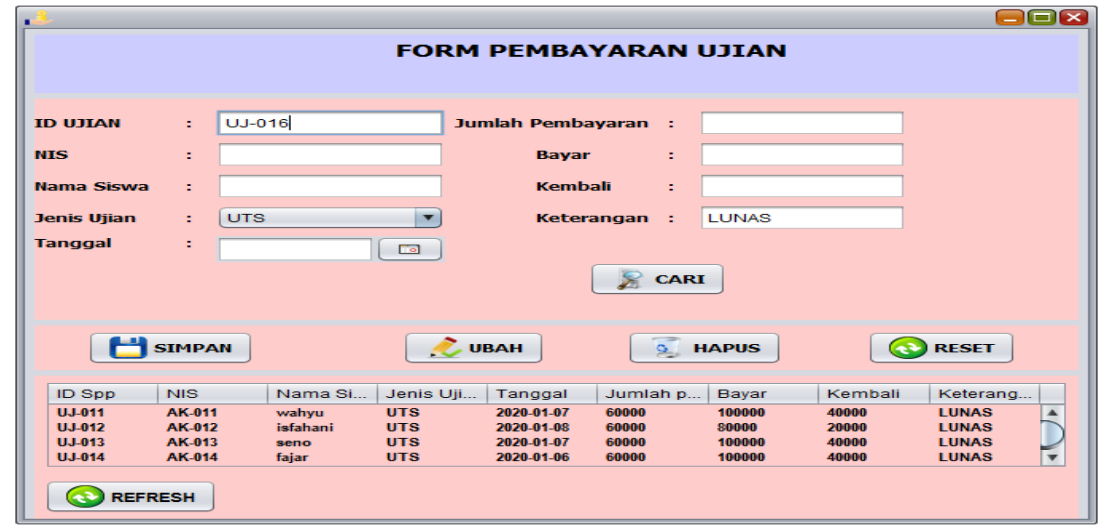

Gambar 9. Menu Data Ujian

Menu input form data pembayaran ujian merupakan form tampilan yang digunakan untuk memasukan data pembayaran ujian, selain menyimpan data ujian, user juga dapat mengubah, mencari dan menghapus data siswa. Input form data pembayaran spp nantinya digunakan sebagai sebagai bukti pembayaran ujian.

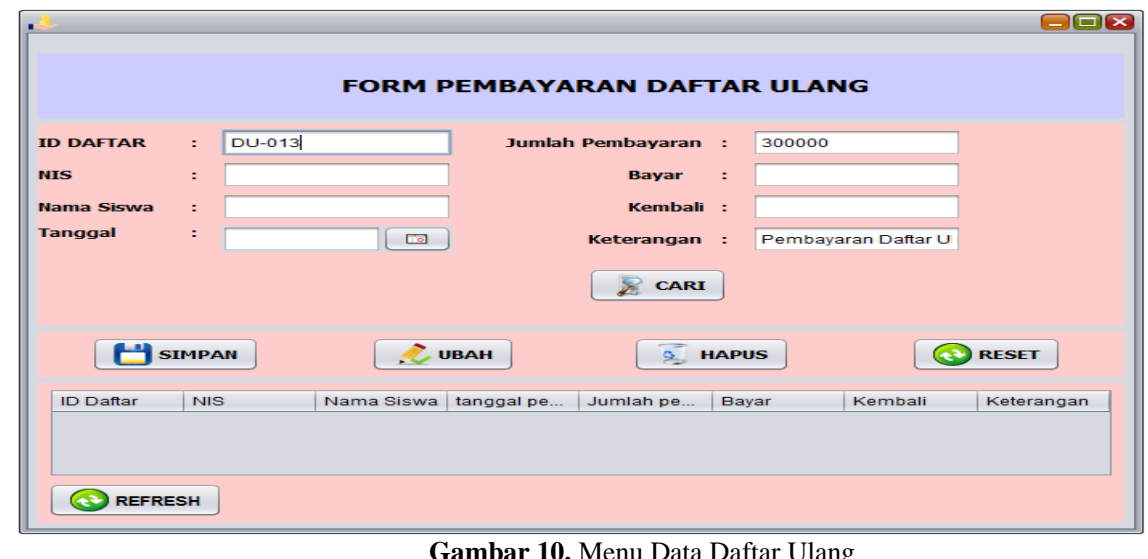

Gambar 10. Menu Data Daftar Ulang 
Мепи input form data pembayaran daftar ulang merupakan form tampilan yang digunakan untuk memasukan data pembayaran daftar ulang, selain menyimpan data daftar ulang, user juga dapat mengubah, mencari dan menghapus data siswa. Input form data pembayaran daftar ulang nantinya digunakan sebagai sebagai bukti pembayaran daftar ulang.

\section{SIMPULAN}

Aplikasi sistem yang dibuat ini dapat mempermudah petugas tata usaha dalam pengolahan data administrasi keuangan administrasi keuangan sekolah. Aplikasi sistem administrasi keuangan sekolah ini mempunyai fitur pencarian sehingga dapat memudahkan petugas tata usaha dalam melakukan pencarian data seperti data siswa, data spp, data ujian dan data daftar ulang. Aplikasi sistem administrasi keuangan sekolah menggunakan bahasa program java dan database MySQL ini mampu mengatasi permasalahan kerangkapan data dan meminimalisir kesalahan data.

\section{DAFTAR PUSTAKA}

Arif, Achmad Yusron. (2019). Pengertian MySQL, Kelebihan Dan Kekurangan. 2019.

Adyanata, L. (2016). Basis Data Dasar. In Deepublish.

Heru, rohman. (2019). pengertian java. In belajar java.

Ibrahim, A. (2013). Pengertian Aplikasi dan Sejarah Perkembangan Aplikasi _ Pengertian dan Definisi.

Mulyadi. (2016). Pengertian sistem menurut mulyadi. In Sistem Akuntansi.

Susanti, E. D. (2017). Sistem Informasi Administrasi Keuangan Sekolah Berbasis Web di SMK YP 17 Selorejo. Journal of Information and Technology, 5(1), 53-58. https://doi.org/10.1017/CBO9781107415324.004.

Wulansari, N., Purnama, B. E., \& Wardati, I. U. (2013). Sistem Informasi Pengelolaan Keuangan Sekolah Pada Sekolah Menengah Kejuruan SMK PGRI 1 Pacitan. Indonesian Journal On Networking and Security, 5700(November), 17. 